\title{
Knowledge, Attitude and Practice toward legalization of abortion among female students of Sabiyan secondary and preparatory school, Dire Dawa, Eastern Ethiopia, 2018. A descriptive cross-sectional study
}

\author{
Legesse Abera ${ }^{\circledR 1}$, Adisalem Debebe ${ }^{\circledR 2}$ \\ ${ }^{1} \mathrm{MPH}$ in Reproductive Speciality, Clinical Coordinator, Department of Midwifery, College of Medicine and Health Sciences, Dire Dawa University, Dire Dawa, Ethiopia, \\ ${ }^{2}$ Msc in Epidemiology and Health Informatics, Department of Public Health, College of Medicine and Health Sciences, Dire Dawa University, Dire Dawa, Ethiopia.
}

\section{Abstract}

Background: Ethiopian abortion law is relatively liberal, but due to lack of knowledge and negative attitude toward legalization of abortion among most women, shortage of safe abortion services provision and significant amount of sociocultural pressures women still go to unsafe abortion service. So the objective of this study was to assess the knowledge, attitude and practice toward legalization of abortion among female students of Sabiyan secondary school, Dire Dawa, March 20-30/ 2018. Subjects \& Methods: The study was conducted in Dire Dawa city, in Sabiyan high school. An institutional based cross-sectional survey was employed on randomly selected female students. Data was collected using pre- tested self-administered questionnaire and analyzed using computer software SPSS version 24.0. Tables, graphs and charts were used for some variable to describe the results of the study. Results: A total of 320 regular female students were included making the response rate of $100 \%$. Ethiopian abortion law was assessed only 40 (12.5\%) of participants were knowledgeable and only $98(30.6 \%)$ of the respondents were having positive attitude. Out of $24(7.5 \%)$ who ever get pregnant, $15(4.7 \%)$ seek for unsafe abortion and only $7(2.2 \%)$ were having experience (practice) of legal abortion. Conclusion: there was a low level of knowledge of the revised Ethiopian abortion law among study participants and majority of the participants had a negative attitude towards legal abortion services and only few of them had practice of legal abortion. So focusing on awareness creation strategy by each stakeholder is an important.

Keywords: Knowledge, Attitude, Practice, Legalization of Abortion, High School Female Students

Corresponding Author: Legesse Abera, MPH in Reproductive Speciality, Clinical Coordinator, Department of Midwifery, College of Medicine and Health Sciences, Dire Dawa University, Dire Dawa, Ethiopia.

E-mail: legesseabera07@gmail.com

Received: 9 September 2019

Revised: 20 November 2019

Accepted: 27 November 2019

Published: 6 July 2020

\section{Introduction}

Abortion is defined by world health organization as the termination of pregnancy by removal or expulsion of conceptus tissues from the uterus before $28^{\text {th }}$ week of gestation for developing countries and 20 weeks of gestation for developed countries. Abortion can occur either spontaneously or could be induced. ${ }^{[1]}$ Since illegal abortions have high mortality and morbidity rates, legalizing abortion is highly debatable issue among health policy makers worldwide. Some abortions laws are based on a medical model, for example, England define abortion as a solution to medical problem. This is only allowed in order to prevent the risk of physical, psychological damage to a pregnant woman. United States law defines the decision to have an abortion as a matter of rights that is a woman has the right to make private decision for herself about something that will affect her without the interference of government. ${ }^{[2]}$

Until 2005 the Ethiopian penal code permitted abortion only to save the pregnant woman's life, but in 2005 the penal code was amended to permit abortion under a much broader set of circumstances like in the case of rape, incest or fetal impairment, if pregnancy continuation or birth would endanger the health woman or fetus, if the woman has physical or mental disabilities, and if the woman is a minor who is physically or mentally unprepared for childbirth. In most cases, a woman's statement is sufficient to establish the legal indication for, and allow her to obtain, the abortion but many Ethiopian women remain confused or unsure of their rights and don't know how to prevent unplanned pregnancies. ${ }^{[3]}$ Due to lack of knowledge of legal rights, negative attitude, shortage of safe abortion services provision and sociocultural pressures women still go to unsafe abortion service. The Ethiopian 
government has accomplished a great deal since adopting the revised penal code. However, despite the progress, women especially young girl continue to be confronted by obstacles to seeking safe abortion service. ${ }^{[4]}$

Knowledge about abortion law among women is very important because it has implications for access to legal abortion services. The proportion of women with correct knowledge of the legal status of abortion is both indicators for measuring access to information about safe abortion. ${ }^{[5]}$ In order to make significant improvement towards access to safe abortion, the national abortion law should be known by the youth. With increased knowledge and awareness of legalization of abortion, young women empowered to seek safe abortion care since they are especially vulnerable to unsafe abortion practices. ${ }^{[6]}$ To practices this legislations, the knowledge and attitude of the population is important. And as much as we reviewed different literature there is no study conducted in our study area in this topic which gives us some base line data. Therefore the aim of this study was to assess knowledge, attitude and practice of legalization of abortion among Sabiyan secondary and preparatory school female students.

\section{Subjects and Methods}

An institution based cross-sectional study on female students in Sabiyan secondary and preparatory school in Dire Dawa was conducted from March 20-30/2018. A stratified sampling method was used based on the student's grade $(9-12)$ and then three sections were selected by simple random method from each grade, and identified the total number of students from each section. ${ }^{[7-10]}$ Then, the calculated sample size was proportionally allocated to each selected section according to the number of female students they consist. Finally, the study subjects were taken from each section by simple random method. A sample size of 320 subjects were determined by using single population proportion, considering $\mathrm{P}=48.2 \%$ and adding $10 \%$ non-response rate. ${ }^{[11]}$ Data was collected by using the prepared self-administered questionnaires after orientation given to the study participants by 8 data collectors and facilitators (4 health workers and 4 teachers). Since the topic is sensitive issue and majority of participants were young, the health workers facilitate the consent by wearing gown and gave to the participants a detail description mainly on the aim of the study, on each part of questionnaires, about consents, the right to participate or not, the right to withdraw at any time, and confidentiality issues and they secure the oral consent then distributed the questionnaire to each participants and again obtained the written consent. For those study subjects age less than 18 years, the data collectors were go to their home and explained the aim of the study to their family and obtained the consent. Data was cleaned, edited, coded and entered to SPSS version 24.0 for analysis. Chi-square test was done to determine any relationship between the main variables. Frequencies, proportions and summary statistics was used to describe the study population in relation to relevant variables. Tables and graphs were used for some variable to describe the results of the study. The study was carried out after getting permission from the ethical clearance committee of the University. Then, data was collected after getting both oral and written informed consent from all participants.

The following operational definitions were used in the study

- Knowledgeable - respondents those who responds all (five) indications of legal abortion in Ethiopia.

- Fairly knowledgeable: - respondents those who responds 3-4 out of five indications of legal abortion in Ethiopia.

- Poorly knowledgeable: - respondents those who respond to less than three indications of legal abortion in Ethiopia.

- Positive attitude: - respondents those support or agree to at least half of positively stated statement about legalization of abortion.

- Negative attitude: - respondents those support or agree to less than half of positively stated statement about legalization of abortion.

- Practice: Those students who have experienced/ practiced legal abortion (safe abortion) services, otherwise no practice/experience.

\section{Results}

\section{Socio-demographic characteristics of respondents}

A total of 320 students were included in the study making the response rate of $100 \%$. The mean ages of respondents were $18.0 \pm 1.9$ years. More than half of the study subjects, 170 (53.1\%) were Muslim in religion. Majority 289 (90.3\%) of participants were single. Living condition and residence of respondents were assessed and majority of them, 271(84.7\%) and $274(85.6 \%)$ were living with parents and urban residence respectively. Most of the respondent's fathers and mothers, $137(42.8 \%)$ and $190(59.4 \%)$ respectively were unable to read and write (table 1). With regard to ethnicity of respondent nearly half of them 141(44.1\%) were Oromo (Figure 1).

\section{Knowledge of respondents on legalization of abortion}

The finding of this study shows that about 152 (47.5\%) respondents have heard about abortion. Respondents knowledge on the meaning of abortion was assessed and among 152 participants $21(6.6 \%)$ of them responded that abortion is absence of menstruation and 18 (5.6\%) of them responded that abortion is expulsion of fetus at an early week of pregnancy. Among those respondents who knew complication of unsafe abortion $92(60.5 \%)$ and $60(39.5 \%)$ of them knew bleeding and infertility are most common serious complications of unsafe abortion respectively. Knowledge on existence of abortion law in 
Ethiopian were assessed and nearly half of the respondents, $152(47.5 \%)$ knew existence of abortion law in Ethiopia and the rest didn't. Out of those participants knew the existence of abortion law, only $40(12.5 \%)$ of them answered all circumstances under which abortion is permitted and they were considered as knowledgeable, and $50(15.6 \%)$ of the participants were fairly knowledgeable (Figure 3 ). Fifty four (16.85\%) of participants were obtained information on Ethiopian abortion law from mass media and the other 54(16.85\%) of them from school (Table 2). Among participants knew the circumstances under which abortion is permitted in Ethiopia , 60 (18.75\%) of them were responded abortion is permitted if the age of the pregnant mother were less than 18 years , 51 (15.9\%) of them were responded abortion is permitted if pregnancy is a risk to the life of mother or fetus or both , $50(15.6 \%)$ of them said that 'abortion is permitted if pregnancy is after rape or incest', $43(13.4 \%)$ of the participants were responded abortion is permitted if the pregnant mother has serious mental or physical incapacity and $40(12.5 \%)$ of them were responded that abortion is permitted in case of congenital anomalies of the fetus (Figure 2).

\section{Attitude toward legalization of abortion}

Considering attitude, $152(47.5 \%)$ of the students do not agree for legal abortion services and only $98(30.6 \%)$ agree with this regard. Religion and culture accounted for the highest proportion as reasons for they didn't agree (Figure 3). Nearly half of the study subjects $152(47.5 \%)$, believed that legal abortion is a sin and majority (69.7\%) agree that to get abortion services females should get partners permission. Respondents future plan of any unwanted pregnancy, $35(10.9 \%)$ of the study subjects will go to health institution for legal abortion' and 285 (89.1) of the participants will deliver it normally'. Two hundred fifteen (67.2\%) respondents will discuss about what happened with partner or parents. The general attitude of respondents on circumstances under which abortion is legalized, 98 (30.6\%) of them were having positive attitude and majority $(69.4 \%)$ of them having negative attitude on the issues (Table 3).

As indicated in figure 5, 20\% of the participants agree legal abortion if there is maternal health problem encountered, $31 \%$ agree if there is fetal deformity, $21 \%$ agree if there is maternal mental or physical impairment, $32 \%$ agree if age of mother less than 18 years, and $35 \%$ agree that if the pregnancy is as a result of rape or incest. The respondents general attitude was assessed, 98 (30.6\%) of the respondents were having positive attitude and the rest having negative attitude.

\section{Practice of legalization of abortion}

One hundred eighteen participants (36.9\%) ever had boyfriend (ever partnered), among whom 45 (14.1\%) were ever had sexual intercourse. Among all participants 24 (7.5\%) has history of previous pregnancy of which 22 of them unwanted and 2 wanted pregnancy. Out of all having history of pregnancy, majority $15(4.7 \%)$ were aborted illegally by traditional methods, $7(2.2 \%)$ of total study participants aborted in health institutions and only $2(0.6 \%)$ of pregnancy end up with birth (table 4 and figure 6).

\section{Discussion}

Safe abortions performed based on our country legal status and medical guidelines carry very low risk of complications while unsafe abortions increase the vulnerability of maternal morbidity and death, representing one of the major causes of preventable maternal deaths. Thus provision of proper abortion care services helps to prevent the complications in case of unwanted pregnancies. Our study finding showed that, $152(47.5 \%)$ heard about abortion the rest didn't. Out of those participants heard about abortion, $46.2 \%$ of participants knew the meaning of abortion correctly. This finding was lower than a study done among school girls in Goma, Democratic Republic of Congo (61.3\%), study done among public secondary school students in Addis Ababa (81.7\%) and study conducted at Yirga chefe, Ethiopia (78.21\%) .$^{[7,10,12,13]}$ This could be because of the better availability and accessibility of information from alternative source (like newspapers, school clubs, peer education, youth center etc.) that help to increase awareness in those study areas.

Research shows that most youth experienced unprotected sex and unintended pregnancy because they are in a sexually active age. In such cases, knowledge about abortion law could play a critical role in reducing unintended birth and unsafe abortion which contribute for maternal death. This study showed that $152(47.5 \%)$ of the respondent knows existence of abortion law in Ethiopia. This finding was similar with the study conducted in Mexico (46\%), and study conducted at Yirga chefe $48.2 \%{ }^{[8,12]}$ But our study finding lower than a study done in Latvia (53\%). ${ }^{[14]}$ In other way our study finding was higher than the study conducted in Ghana, $11 \%,{ }^{[9]}$ and study done in Mizan Aman town of Ethiopia which was only 5.7\% knew about the legalization of abortion. ${ }^{[15]}$ This variation might be due to lack of uniform information dissemination strategy throughout the country. This means that the majority of women do not get information on their own affairs. The other explanation could be some of the studies conducted five years back at which source of information minimal at that time.

The finding of this study indicated that among participants knew the circumstances under which abortion is permitted in Ethiopia, only $40(12.5 \%)$ of them were knowledgeable. This finding was low which is similar with the study done in Zambia $16 \%,{ }^{[16]}$ and study done in Mizan Aman town of Ethiopia only $5.7 \%$ knowledgeable on legalization of abortion. ${ }^{[15]}$ This could be because of knowledge of liberalization of laws does not diffuse easily. But the result was lower than study 
done in other part of the country. The study conducted in Harar town, 35.7\% and the study conducted in Arba Minch town revealed that $23.4 \%$ of female students have knowledge towards the legislation of abortion. ${ }^{[12,17]}$ The result was again lower than study result in South Africa and Armenia which was $32 \%$ and $31 \%$ of females knew that, abortion is legal under any condition respectively. ${ }^{[10,18]}$ The possible difference might be because of the difference in culture and socio economic condition and also might be due to poor information dissemination to the target population in the study area. School and mass medias are the major source of information, $16.85 \%$ and $16.85 \%$ respectively. This finding were lower than the study conducted at Addis Ababa which were 110 (45\%) and 95 (41\%) respectively, this could be because of strong school health program and clubs and also could be because of high coverage of different medias in Addis Ababa than our study area. ${ }^{[12]}$

The study result revealed that 98 (30.6\%) of the respondents were having positive attitude while majority of respondents were having negative attitude toward legalization of abortion and only $98(30.6 \%)$ agree with a woman with unwanted pregnancy should get abortion services. This study finding was similar with the study conducted in Mexico among Mexican youth $22 \%$, in Armenia 30\%, in Debra Markos hospital $23 \%{ }^{[8,15,18]}$ Again $69.6 \%$ of the students agree that abortion is a sin. Contrary to this finding a study conducted in Ghana $48 \%$ of the participants said that abortion is a sin, religion added to culture is the reasons for young people to believe that abortion is a $\sin .{ }^{[9]}$ This could be because of Muslim religion might be consider abortion as a sin in both study area and could also be because of Changing community attitudes might be challenging particularly on abortion since its sensitive topic.

Safe abortion is an effective means of preventing unintended birth and unsafe method of abortion, but unfortunately the large numbers of youth are unaware of it. This study revealed that among all participants $24(7.5 \%)$ has history of previous pregnancy of which $4.7 \%$ were aborted illegally by traditional methods and $2.2 \%$ aborted in government health institutions. This finding is similar with the study conducted in Arba Minch which indicates $2.8 \%$ of participants induced legal abortion in government health institution. ${ }^{[19]}$ This similarity could be because of both conducted among youth of similar institution with similar age group.

\section{Conclusion}

A high proportion of participants have no knowledge of the legal status of abortion in Ethiopia, and also most of them have negative attitudes towards legal abortion. Religion and culture contributed for the negative attitude toward legalization of abortion. It's also indicated that only few students who were encountered unwanted pregnancy had experience of legal (safe) abortion services. So focusing on awareness creation strategy by each stakeholder is an important.

\section{References}

1. Rouse CE, Eckert LO, Babarinsa I, Fay E, Gupta M, Harrison MS, et al. Spontaneous abortion and ectopic pregnancy: Case definition \& guidelines for data collection, analysis, and presentation of maternal immunization safety data. Vaccine. 2017;35(48 Part A):6563-6574. Available from: https://dx.doi. org/10.1016/j.vaccine.2017.01.047.

2. Curtis C, Faundes A, Yates A, Wiklund I, Bokosi M, Lacoste M. Postabortion Family Planning Progress: The Role of Donors and Health Professional Associations. Glob Health Sci Pract. 2019;7(Suppl 2):S222-S230. Available from: https://dx.doi. org/10.9745/GHSP-D-18-00334.

3. Zenebe M, Haukanes $\mathrm{H}$. When abortion is not within reach: Ethiopian university students struggling with unintended pregnancies. Int J Equity Health. 2019;18:23. Available from: https://dx.doi.org/10.1186/s12939-019-0925-2.

4. Habtemariam MK, Semegn ST. Setting health sector priorities: a brief overview of Ethiopia's experience. Cost Eff Resour Alloc. 2018;16(Suppl 1):46. Available from: https://dx.doi.org/ 10.1186/s12962-018-0117-8.

5. Women's Awareness and Knowledge of Abortion Laws: A Systematic Review. PLoS One. 2016;11(3):e0152224. Available from: https://dx.doi.org/10.1371/journal.pone.0152224.

6. White K, Potter JE, Stevenson AJ, Fuentes L, Hopkins K, Grossman D. Women's Knowledge of and Support for Abortion Restrictions in Texas: Findings from a Statewide Representative Survey. Perspect Sex Reprod Health. 2016;48(4):189197. Available from: https://dx.doi.org/10.1363/48e8716.

7. Paluku LJ, Mabuza LH, Maduna PMH, Ndimande JV. Knowledge and attitude of schoolgirls about illegal abortions in Goma, Democratic Republic of Congo. Afr J Prim Health Care Fam Med. 2010;2(1). Available from: https://dx.doi.org/10.4102/ phcfm.v2i1.78.

8. Becker D, Garcia SG, Larsen U. Knowledge and Opinions about Abortion Law among Mexican Youth. Int Fam Plan Perspect. 2002;28:205-205. Available from: https://dx.doi.org/ $10.2307 / 3088223$.

9. Institute G. Advancing sexual and reproductive health worldwide through research, policy analysis and public education. Abort Ghana. 2010;1(2):1-4.

10. Morroni C, Myer L, Tibazarwa K. Knowledge of the abortion legislation among South African women: a cross-sectional study. Reproductive Health. 2006;3(1):7-7. Available from: https://dx.doi.org/10.1186/1742-4755-3-7.

11. Debela TF, Mekuria MS. Knowledge and attitude of women towards the legalization of abortion in the selected town of Ethiopia: a cross sectional study. Reprod Health. 2018;15(1):190. Available from: https://dx.doi.org/10.1186/ s12978-018-0634-0.

12. Debela TF, Mekuria MS. Knowledge and attitude of women towards the legalization of abortion in the selected town of Ethiopia: a cross sectional study. Reproductive Health. 2018;15(1):190-190. Available from: https://dx.doi.org/10. 1186/s12978-018-0634-0. 
13. Bantie GM, Aynie AA, kassa Assefa M, Kasa AS, Kassa TB, Tsegaye GW. Knowledge and attitude of reproductive age group (15-49) women towards Ethiopian current abortion law and associated factors in Bahir Dar city, Ethiopia. BMC Women's Health. 2020;20(1):9797. Available from: https://dx.doi.org/10.1186/s12905-02000958-y. doi:10.1186/s12905-020-00958-y.

14. Melgalve I, Lazdane G, Trapenciere I, Shannon C, Bracken H, Winikoff B. Knowledge and attitudes about abortion legislation and abortion methods among abortion clients in Latvia. Eur J Contracept Reprod Health Care. 2005;10(3):143-150. Available from: https://dx.doi.org/10.1080/13625180500332224.

15. Adera A. Assessment of Knowledge, Attitude and Practice Women of Reproductive Age Group towards Abortion Care at Debre Markos Referral Hospital, Debre Markos Ethiopia. Sci J Public Health. 2015;3(5):618-618. Available from: https: //dx.doi.org/10.11648/j.sjph.20150305.14.

16. Cresswell JA, Schroeder R, Dennis M, Owolabi O, Vwalika $\mathrm{B}$, Musheke $\mathrm{M}$, et al. Women's knowledge and attitudes surrounding abortion in Zambia: a cross-sectional survey across three provinces. BMJ Open. 2016;6(3):e010076. Available from: https://dx.doi.org/10.1136/bmjopen-2015-010076.

17. Geleto A, Markos J. Awareness of female students attending higher educational institutions toward legalization of safe abortion and associated factors, Harari Region, Eastern Ethiopia: a cross sectional study. Reproductive Health. 2015;12(1):1-9. Available from: https://dx.doi.org/10.1186/s12978-015-0006$\mathrm{y}$.
18. Chong E, Tsereteli T, Vardanyan S, Avagyan G, Winikoff B. Knowledge, attitudes, and practice of abortion among women and doctors in Armenia. Eur J Contracept Reprod Health Care. 2009;14(5):340-348. Available from: https://dx.doi.org/ 10.3109/13625180903131348.

19. Animaw W. Awareness and Attitude to Liberalized Safe Abortion Services among Female Students in University and Colleges of Arba Minch Town, Ethiopia. Sci J Public Health. 2014;2(5):440-440. Available from: https://dx.doi.org/10. 11648/j.sjph.20140205.20.

Copyright: (C) the author(s), 2020. It is an open-access article distributed under the terms of the Creative Commons Attribution License (CC BY 4.0), which permits authors to retain ownership of the copyright for their content, and allow anyone to download, reuse, reprint, modify, distribute and/or copy the content as long as the original authors and source are cited.

How to cite this article: Abera L, Debebe A. Knowledge, Attitude and Practice toward legalization of abortion among female students of Sabiyan secondary and preparatory school, Dire Dawa, Eastern Ethiopia, 2018. A descriptive cross-sectional study. Asian J. Med. Res. 2020;9(2):1-5.

DOI: dx.doi.org/10.47009/ajmr.2020.9.2.CM1

Source of Support: Nil, Conflict of Interest: None declared. 